\title{
Oral Corrective Feedback and Learners' Uptake in Teenage EFL Class
}

\author{
Ivana Ovilia \\ English Department, Faculty of Languages and Literature, Petra Christian University, Siwalankerto 121- \\ 131, Surabaya 60236, INDONESIA \\ E-mail: ivana.ovilia@gmail.com
}

\begin{abstract}
This study was done to find out: (1) the types of oral corrective feedback (CF) strategies, (2) the types of learners' uptake, and (3) the types of learners' uptake elicited in relation to the teacher's types of oral CF. In order to answer the research questions, the writer applied two theories, Sheen and Ellis (2011) for oral CF strategies and Panova and Lyster (2002) for the types of learners' uptake, as the guideline. This study used qualitative approach, using audio recording. The findings showed that there were forty three (43) oral CF occuring in the class, and forty one (41) uptakes elicited in relation to teacher's oral CF. There were 2 (two) oral CF which did not result in uptake. Six (6) out of nine (9) oral CF strategies and seven (7) out of ten (10) types of learners' uptake occurred in the class. Didactic Recast was the most frequently applied oral CF strategies, whereas Repetition was the most frequently applied learners' uptake type. There were 18 types of oral CF strategies and learners' uptake sequences occurring in the class, and the most occurring sequence was Didactic Recasts - Repetition, with total 11 times. There were some possible reasons why uptakes did not occur: learners were taking too long to answer or the teacher did not want to wait longer expecting that learner had already known the correct form through prior explanation. In order to maintain the class running smoothly, the teacher sometimes was faced to a situation when none uptakes were elicited from the learners.
\end{abstract}

Keywords: corrective feedback, oral corrective feedback, uptake

\section{INTRODUCTION}

English is popularly used among people in many countries for communication in this global era. Because of that, many people begin to realize the importance of learning English as English becomes one of the most used languages in the world. In learning English as a second language, learners also have the tendency to make errors, because learners are exposed to the language which is not their first language. According to Littlewood (1984, p. 17), "Errors play an important role in learning process". Errors are part of language learning process for second language learners, and that commonly happens among learners. That is why, the role of teachers is very important to help the learners correct their errors.

In response to learners' errors in their language learning, teachers provide corrective feedback to correct the errors and help the learners to develop their skills. As cited from Sheen and Ellis (2011, p.593), corrective feedback (CF) refers to the "feedback that learners receive on the linguistic errors they make in their oral or written production in a second language". CF helps learners to understand what errors that they made. CF has two types, oral and written, and both of them are considered important for language teaching (Sheen and Ellis, 2011). Especially for oral CF, which according to Mendez et al. (2011, p.255) is "ambiguous and unsystematic corrective feedback techniques or approaches". Teachers may use oral CF differently in their classroom and that encouraged the writer to do a study focusing only on oral CF. CF also works by causing learners to know what errors they have made, and may assist learners to repair or correct their errors. This is known as learners' uptake, defined as "a student's utterance that immediately follows the teacher's feedback and that constitutes a reaction in some way to the 
teacher's intention to draw attention to some aspect of the student's initial utterance" [Lyster and Ranta, 1997, as cited in Panova and Lyster, 2002, p. 585]. Learners' uptake also plays an important role in language teaching and learning, because it helps the learners to develop their knowledge by correcting their errors. Both oral CF and learners' uptake have relation that helps learners in acquiring second language. That is why, the writer was inspired to do a study about oral CF and learners' uptake in an EFL classroom.

The main theories of this study are oral CF strategies proposed by Sheen and Ellis (2011) and learners' uptake proposed by Panova and Lyster (2002). There are nine types of oral CF proposed by Sheen and Ellis (2011): conversational recasts, didactic recasts, explicit correction, explicit correction with metalinguistic explanation, repetition, clarification requests, metalinguistic clue, elicitation, and paralinguistic signal. For the learners' uptake, there are ten types of learners' uptake, which are divided into two major categories, repair and needs repair. There are four types of uptake which are categorized as repair; self-repair, peer repair of error, repetition and incorporation of feedback (Panova and Lyster, 2002). While the remaining six types, acknowledgement, same error, different error, off-target, hesitation, and partial repair, are categorized as needs repair (Panova and Lyster, 2002).

The EFL class that the writer analyzed was from an English course institution in Surabaya. The level of the class that the writer chose as her study was teenager general. The writer chose teenager learners because teenager learners have the ability to think critically and hypothesize, which is not always available to learners at other ages (Lewis, 2007).

This study was done to find out three answers to the question 1) What are the types of oral CF strategies that occur in Teenage EFL class? 2) What are the types of learners' uptake that occur in Teenage EFL class? and 3) What types of learners' uptake that are elicited in relation to the teacher's types of oral CF?

\section{METHOD}

This study used qualitative approach. There are three reasons why this study is qualified as qualitative research. First, most of the data and the analysis were in the form of words. Second, the data were taken in a natural setting. Third, there was a limited and small number of participants. Fourth, the data were based on the researcher's interpretation (Dörnyei, 2007).

The sources of the data for this study were mainly from the teacher and learners' interaction in the classroom. The data of this study were from the teacher' utterances, as well as the learners' uptake from the feedback. The sole instrument for this study was the writer herself.

In order to get all the data, the writer chose an EFL class from an English course institution in Surabaya. The writer chose this institution because it has been around for a long time. The writer applied some steps in collecting the data. First of all, the writer contacted the institution to ask for permission to observe one of their classes. The writer also met the coordinator of the institution to ask some information regarding the observation. After getting the permission, the writer started the data collection.

The writer collected the data by audio recording the classroom activities of the teenage EFL class for four meetings. One class meeting lasted for about 90 minutes. When recording the classroom activities, the writer sat at the back of the class and recorded the classroom interaction and made sure not to distract the learners. The writer also took notes for things that were related to the classroom interaction. The writer came to the class before the class started and left after the class ended. The writer only got permitted to do an audio taping observation. Because of that, the writer could not analyze one of the types of oral CF strategies, 
Paralinguistic Signal, which refers to a teacher's way in correcting a learner's error without using any verbal signs to prompt correction from the learner (Sheen and Ellis, 2011).

For the transcription, the writer used detailed transcription. Detailed transcription is not only focused on the content of the data, but also on the details of the data (Elliott, 2005). The writer adapted the transcription system by Van Lier (1988) and Johnson (1995), which is cited in Walsh (2011). The writer also distinguished the font for teacher's oral CF and learners' uptake, underlined for oral CF and bold for learners' uptake.

In order to analyze the data, the writer transcribed all the data first. After that, the writer analyzed the teacher and learners' utterances that contained the oral CF and learners' uptake, and categorized them based on the oral CF strategies and learners' uptake theories that were used. The writer also took notes in each oral CF and learners' uptake that happened in the conversation. After that, the writer also counted the oral CF and learners' uptake types found in the teacher-learners conversations. The total was based on frequency of occurrence.

\section{FINDINGS AND DISCUSSION}

Based on the data, there are forty one uptakes that are elicited in relation to teacher's oral CF, and two times where the teacher's oral CF did not result in learner's uptake. The writer also found that the most occurring teacher's oral CF and learners' uptake are didactic recasts and repetition. Below are the explanations of each type of oral CF strategies and learners' uptake found in the class.

\section{Types of Oral CF Strategies}

Six out of nine types of oral CF strategies proposed by Sheen and Ellis (2011) were found in the class. The six types of oral CF strategies found in the class were Didactic Recasts, Explicit Correction, Explicit Correction with Metalinguistic Explanation, Repetition, Elicitation and Metalinguistic Clue. In addition, the writer found from this study that didactic recast was mostly used type of oral CF strategies. Below is the further explanation of each type of oral $\mathrm{CF}$ strategies.

\section{a. Didactic Recasts}

Didactic recasts take place when the "correction takes the form of a reformulation of a student utterance even though no communication problem has arisen" (Sheen and Ellis, 2011, p. 594). This type of oral CF strategy is found to be the most frequently used in the class. One of the example of teacher's didactic recasts can be seen in the underlined statement below $\mathrm{T}:=$ So... what is the example of past simple?

L1: she shower last night

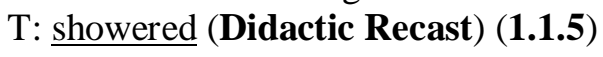

The didactic recast in the extract is used by the teacher to correct the learner's grammar. It is considered as didactic because the teacher's focus is on the learner's grammar accuracy and there is no communication problem which has arisen. The learner used the incorrect form of verb in relation of past simple by saying 'shower' instead of 'showered'. The teacher provided didactic recasts to show the correction.

\section{b. Explicit Correction}

Explicit correction happens when the "correction takes form of a direct signal that the errors has been committed and the correct form has been supplied" (Sheen and Ellis, 2011, p. 594). Based on the data, explicit correction mostly occurred when the learners had 
already made several errors but the repair has not been made by the learners yet. Below is the example of explicit correction.

T: iya basic stucturenya. Kalo basic structurenya of past continuous sentence yang positive itu apa? It starts from?

(Yes, the basic structure. What is the basic structure of past continuous in positive sentence? It starts from?)

L1: while?

T: no I mean the basic thing. Without when or while. (Metalinguistic Clue) (2.1.2)

L1: ed? (Different Error) (2.2.1)

$\mathrm{T}$ : ok, I think you don't understand my question. Maksudnya (I mean), you begin with the subject, this is the basic thing. (Explicit Correction) (2.1.3)

The learner was asked about the structure of past continuous in positive form. The learner still made an error, even after the teacher gave the first feedback (metalinguistic clue). The teacher eventually provided explicit correction to correct the error directly.

\section{c. Explicit Correction with Metalinguistic Explanation}

Explicit correction with metalinguistic explanation occurs when the signal has already been done and the teacher provides the correct form, with an addition of metalinguistic comment (Sheen and Ellis, 2011). Based on the data, this type of feedback only happened once. This occurred when the learners previously made the same error and the learners still made the same error when they were asked about similar question. Below is the example of explicit correction with metalinguistic explanation.

L3: a lot of students have... got part-time job... fif-fifty percent of sixteen years old--$\mathrm{T}$ : sixteen-year-olds. Jangan kebalik. Sixteen years old is for age while sixteen year olds is for.... Is for kids.... eh teenager yang umurnya sixteen... in this context is sixteen year olds. (Explicit Correction with Metalinguistic Explanation) (3.1.4)

(sixteen-year olds. Don't say the opposite. Sixteen years old is for age while sixteen year olds is for.... Is for kids.... Whose age is sixteen... in this context is sixteen year olds.)

The learner was asked to read aloud the reading passage in the book. Previously, the learner always made error in saying 'sixteen year olds' with 'sixteen years old'. The teacher provided explicit correction with metalinguistic comment as additional information to the learner, while correcting the error as well.

\section{d. Repetition}

Repetition occurs if the teacher only repeats the error produced by learners without highlighting the error (Sheen and Ellis, 2011). The purpose of this type of feedback is to get learners' awareness about the error and to prompt a self-correction from the learners. Below is the example of repetition.

L1: did she studied yesterday?

T: did she studied? (Repetition) (4.1.3)

Based on the extract above, repetition is used by the teacher to prompt the learner to give a self-correction for her error. The learner used incorrect verb of past simple in question form. The teacher only repeated the learner's sentence, while simultaneously elicited the learner's correct answer.

\section{e. Metalinguistic Clue}

Metalinguistic clue occurs if the teacher gives a brief metalinguistic statement to elicit a correction from the learner (Sheen and Ellis, 2011). Metalinguistic clue also happened to be the second most frequently used oral CF strategies by the teacher. Below is the example of metalinguistic clue that can be seen in the underlined statement. 
L1: who did you saw yesterday?

T: loh Kayla (laughs) verb satu. (Metalinguistic Clue) (4.1.4)

(Kayla (laughs) it's verb one)

The teacher's oral CF is considered as metalinguistic clue because of metalinguistic comment that the teacher gave as a hint to the learner about her error. The learner made a grammatical error in her statement. She used incorrect verb of past tense in wh-question form ('saw' instead of 'see'). The teacher only said 'it's verb one' to the learner as a hint that what she said was incorrect.

\section{f. Elicitation}

Elicitation is defined as an attempt made to verbally elicit the correct form from the learner, for example, a prompting question (Sheen and Ellis, 2011, p. 594). The elicitation strategy was mostly found in the class as teacher wanted to elicit the correct answer from the learner by partially repeating the learner's sentence in a form of question. One of the examples of elicitation taken from the writer's data is shown in the underlined statement below.

L1: she did not showered last night

$\mathrm{T}$ : She did not....? (Elicitation) (1.1.11)

Based on the teacher's elicitation shown from the extract, it can be seen that the teacher only partially repeated the learners' statement while also questioning the learner to elicit a correct answer. The teacher only repeated the first three words of the statement in a questioning tone, to elicit the correction from the learner.

\section{Types of Learners Uptake}

Based on the writer's data, seven out of the ten types of learners' uptake proposed by Panova and Lyster (2002) were found in the class. Three out of seven types were categorized as repair, which were self-repair, peer repair, repetition. Acknowledgement, different error, partial repair and hesitation types found in the class were categorized as needs repair. It was also found that repetition was the most frequently occurring type of learners' uptake. Below is the explanation of each type of learners' uptake.

\section{Repair}

Repair can be defined as "the correct reformulation of an error as uttered in a single turn and not to the sequences of turns resulting in the correct reformulation; nor does it refer to self-initiated repair" (Lyster and Ranta, 1997, as cited in Panova and Lyster, 2002]. Based on the data, there were three types of uptake which are categorized as repair, Self Repair, Peer Repair, Repetition, were found in the class. The three types were also found to be dominant uptake that occurred in the class. Below is the explanation of each learners' uptake which categorized in repair that found in the class.

\section{a. Self-Repair}

Self-repair occurs when teacher's feedback, which does not include the correct form, prompts the learner who committed the error to self-correct (Panova and Lyster, 2002). Based on the data, the writer found that self-repair occurred when the teacher's oral CF did not include correction, only the prompts or clues were given. Below is one of the examples of self repair found in the data.

L1: yeah. Must you slurping when you eating?

$\mathrm{T}$ : must you not....? (Elicitation) (4.1.9)

L1: oh ya. Must you slurp when you eating? (Self-Repair) (4.2.6) 
It can be seen from the extract that the learner self-corrected her error after the teacher elicited the correct answer. The learner corrected 'slurping' with 'slurp' in accordance to the correct grammatical form.

\section{b. Peer Repair}

Peer repair occurs when the learner who makes an uptake is different from the one who made the error (Panova and Lyster, 2002). From the data, peer repair only occured when the teacher's feedbacks only contained prompts or clues, without the correction. In addition, peer repair could happen because the learner who made the error could not provide the correction. Below is the example of peer repair.

L3: were my cat swimming around?

$\mathrm{T}$ : salah to be nya (Metalinguistic Clue) (2.1.8)

(the to be is wrong)

\section{L2: was my cat swimming around? (Peer Repair) (2.3.2)}

From the example above, it shows that L2 repaired the L3's errors. L3 used the incorrect to be form, 'were', for her statement. Instead of L3 corrected her error after the teacher's feedback, L2 corrected the error.

\section{c. Repetition}

Repetition refers to learners' repetition of the correct form provided by the teacher (Panova and Lyster, 2002). In this study, repetition is found to be the most frequently used type of learners' uptake. One of the examples of repetition is shown below.

L3: did he showered last night..?

$\mathrm{T}$ : shower (Didactic recasts) (1.1.12)

L3: did he shower last night? (Repetition) (1.4.1)

It is shown from the extract above that the learner used the incorrect verb for the past simple in question form. She gave an uptake that resulted in repair by repeating the teacher's didactic recast that had already included the correct form.

\section{Needs Repair}

Needs-repair refers to "a situation in which the student has responded to the teacher's feedback move in some way, but the uptake has not resulted in repair" (Lyster and Ranta, 1997, as cited in Panova and Lyster, 2002). Based on the data, there were four types of uptake which were categorized as needs repair, Acknowledgement, Different Error, Hesitation and Partial Repair, were found in the class. Below is the explanation of each types that found in the class.

\section{a. Acknowledgement}

Acknowledgement refers to the uptake by learners who initially produced the utterance that triggered the episode indicating acceptance of feedback (Lyster and Ranta, 1997, as cited in Panova and Lyster, 2002). Based on the writer's data, the learners gave their acknowledgement not only by saying yes but also other acknowledgement acts such as saying 'oh or 'oh iya'. Below is the example of acknowledgement.

T: ok so modals plus subject plus one. Hmm for wh- questions?

L1: wh- questions terus subject?

(wh-questions then subject?)

$\mathrm{T}$ : modals first (Didactic recasts) (4.1.7)

L1: oh (Acknowledgement) (4.2.4)

It is shown above that the teacher asked about the structure of modals in wh-questions form. The learner gave incorrect order of the structure. The teacher gave didactic recast 
by saying the correct form but the learner only said 'oh' as an acknowledgement without repairing her incorrect utterance.

\section{b. Different Error}

Different error refers to uptake by learners that neither corrects nor repeats the error, instead making a new error (Lyster and Ranta, 1997, as cited in Panova and Lyster, 2002). Based on the writer's data, different error mostly happened when the teacher's oral feedback was in the form of prompt or clues. One of the examples of different error is shown below.

L1: subject plus modals

T: subject, modals, and then what? what else after modals? (Elicitation) (4.1.5)

L1: subject plus modals plus to be? (Different Error) (4.2.3)

T: no. It's not to be.. ayo subject plus modals terus? (Elicitation) (4.1.6)

L3: verb one (Peer Repair) (4.4.1)

Referring to the extract above, the learner made another error after the teacher's first oral CF (Elicitation). The teacher asked about the structure of modals in positive form. The learner did not give the complete structure of modals in positive form and the teacher tried to elicit the learner to give complete structure. The learner gave an uptake that did not result in repair ('to be'), which was a different error. Then, the teacher gave elicitation again to the learner and another learner gave the correction instead.

\section{c. Hesitation}

Hesitation refers to a student's act of pausing or hesitating in responding to the teacher's feedback (Lyster and Ranta, 1997, as cited in Panova and Lyster, 2002). The writer found that hesitation mostly occurred when the learners had difficulties in answering the teacher's prompts or clues. Mostly, the learners would only be silent or made an 'hmm' noise as an uptake. Below is the example of hesitation.

$\mathrm{T}:=$ ok kalo contohnya yang were?

(what about the example of 'were'?)

L1: you were sleeping.

T: No. itu lak past continuous. Contextnya masih past simple biasa (Metalinguistic Clue) (1.1.2)

(No, that is past continuous. The context is still in past simple)

L1: you were--- (Hesitation) (1.2.2)

T: You were? Pakai adjective coba. (Metalinguistic Clue) (1.1.3)

(You were? Try to use the adjective.)

L1: hmm.. (Hesitation) (1.2.3)

$\mathrm{T}$ : You were? ..you were.. angry lah (writes on whiteboard) (Explicit Correction)

(1.1.4)

It is shown from the extract above that hesitation occurred because the learner had difficulties in answering the teacher's oral CF. The teacher had already given metalinguistic clues to the learner, but the learner only hesitated to answer the teacher. The teacher eventually gave the explicit correction to the learner as seen in the conversation above.

\section{d. Partial Repair}

Partial repair refers to uptake that corrects only part of the initial error (Lyster and Ranta, 1997, as cited in Panova and Lyster, 2002). Partial repair happened when the learners do not give a fully correction to the error, only part of it that is corrected. One of the examples of partial repair found in the class can be seen below.

L7: she did studied yesterday 
T: loh (laughs) negative lho. (Metalinguistic Clue) (4.1.1)

L7: eh (laughs) she didn't studied yesterday (Partial Repair) (4.8.1)

T: study (Didactic Recasts) (4.1.2)

L7: didn't study (Repetition) (4.8.2)

It can be seen from the extract above that the learner only partially repaired her error in the first uptake. The teacher asked the example of past simple in negative form. The learner made two errors in her answer. When the teacher gave oral CF to the learner, the learner only added the negative symbol 'didn't', but she did not repair the 'studied'. After that, the teacher gave another oral $\mathrm{CF}$ which included the correct form and the learner only repeated the feedback.

\section{Types of Learners' Uptake Elicited in Relation to Teacher's Types of Oral CF}

Based on the data, there are forty one uptakes that are elicited in relation to teacher's oral CF, and there are two occurrences where the teacher's oral CF did not result in learner's uptake. There are 18 types of oral CF strategies and learners' uptake sequences that were found in the class. Below are the explanations of each teacher's oral CF and learners' uptake sequences that occurred in the class.

\section{a. Didactic Recasts - Repetition}

Based on the data, this oral CF and learners' uptake sequence was the most frequently occurring in the class, with the total eleven times. Based on the analysis in all the eleven times that occurred, didactic recasts - repetition sequence happened because the oral CF that the teacher gave had already contained the correct answer, and the learners only repeated the answer, without elaborating their answer.

b. Didactic Recasts - Acknowledgement

Based on the data, this oral CF and learners' uptake sequence only happened twice. Based on the two times of didactic recasts -acknowledgement sequences that occurred, the writer concluded that this happened because the learners were already aware of their error and knew the correct answer through the teacher's oral CF, so they only gave acknowledgement in order that the lesson can be continued.

c. Didactic Recasts - Partial Repair

Based on the writer's data, this sequence only happened once. The learner only partially repaired the error but she did not repair the other part of her error. The teacher also did not elaborate the learner's uptake and continued the lesson. This occurred when the learners read a story from the textbook. From the writer's perspective, there are possibilities that the learner did not fully repair her error unintentionally. The learner was aware of the error and knew the correct answer, but she only partially repaired her error probably because she just want to continue the reading or she forgot to repair the 'years'.

d. Didactic recasts - no uptake

Based on the data, this sequence also only occurred once. The reason why there was no uptake from the learner was because the teacher immediately proceeded to next question. Because of that, there was no chance for the learner to repair the error. In addition, looking from the prior conversation, the teacher was in the middle of explaining about negative form of past continuous tense and wrote the explanation on whiteboard. The teacher also already wrote the structure of the negative form on whiteboard. From the writer's perspective, the teacher may think that the learner was supposed to know already the correct form, so the uptake from the learner was not necessarily to occur. The teacher probably did not want to stick to that problem too long so she proceeded to the next question as seen from the conversation above. 


\section{e. Explicit Correction - Acknowledgement}

Based on the writer's data, this oral CF and learner's uptake sequence occurred four times. Similar to didactic recast - acknowledgement sequence, the learners only gave acknowledgement to the feedback because the learner may already be aware of their error and its correction. In addition, the explicit corrections that the teacher gave already showed the exact error that the learner's made and its correction, so the learner only gave her acknowledgement that showed she understood.

\section{f. Explicit Correction - no uptake}

Based on the data, this sequence only happened once. The teacher numerously gave oral $\mathrm{CF}$ to the learner to correct her error. However, the learner hesitated to respond to the teacher. The teacher eventually gave explicit correction to the learner and proceeded to the next question. In this case, the uptake did not necessarily occur.

g. Explicit Correction with Metalinguistic Explanation - Repetition Based on the data that the writer got, this oral CF and learner's uptake sequence only happened once. Based on the data, the teacher already provided the correction and further metalinguistic explanation to the learner, and the learner only repeated the correction given by the teacher. From the writer's perspective, it is natural that learners only repeat the explicit correction with the addition of metalinguistic explanation because the learner might think that was the best answer for the question given.

\section{h. Repetition - Self Repair}

Based on the data, this sequence occurred twice in the class. Based on the two times of sequence that occurred, the teacher only repeated the learner's sentence with intention to prompt the learner to give the correction. In response of the feedback, the learner just self-corrected the error. The learner understood the repetition that the teacher gave was her way to prompt the learner, so the learner corrected her error. This also shows that the teacher's oral CF did not contain the correct answer.

i. Metalinguistic Clue - Self Repair

Based on the data, the sequence of metalinguistic clue - self repair happened three times. From all the three metalinguistic clue - self repair sequences that happened in the class, it showed that the teacher made her metalinguistic clue clearly so the learners understood that they made an error, and they self-repaired their error.

j. Metalinguistic Clue - Peer Repair

Based on the data, the order of metalinguistic clue - self repair happened three times. From the writer's perspective, looking at all the three metalinguistic clue - peer repair sequences that happened in the class, there is possibility that the first learner (the one who made the error) was already aware and knew the correct answer, but she did not have a chance to repair it orally. Another possibility was the first learner (the one who made the error) was aware, but did not know the correct answer, so another learner corrected it instead. It also shows that the teacher's oral CF did not contain the correct answer.

k. Metalinguistic Clue - Acknowledgement

Based on the data, this type of sequence only happened once. The learner only gave acknowledgement to teacher's oral CF, without further repair to her error. From the writer's perspective, the learner may already understand the error that she made. In addition, the metalinguistic clue that the teacher's gave was already clear enough that the learner's answer was incorrect. The learner did not repair her error in order that the lesson could be continued.

\section{Metalinguistic Clue - Different Error}

Based on the data, the metalinguistic clue - different error sequence happened three times. Based on the three metalinguistic clue - different error sequences that happened in the class, the writer found that all of them have similar situation; the learners failed to understand the teacher's metalinguistic clues. Because of that, the learner produced another error that was different from the initial error. 


\section{m. Metalinguistic Clue - Hesitation}

Based on the data, this sequence happened twice in the class, in one full conversation. Similar to metalinguistic clue - different error sequence, metalinguistic clue - hesitation sequence could happen because there was failure of understanding the teacher's metalinguistic clues from the learner. The teacher already tried to prompt the learner by giving another metalinguistic clue, but the learner still kept hesitating in responding to the teacher. This was also the prior conversation of explicit correction - no uptake order that happened in the class, where the teacher eventually gave the correction to the learner.

\section{n. Metalinguistic Clue - Partial Repair}

Based on the data, this sequence only happened once. The learner only partially repaired her error. From the writer's perspective, the learner possibly originally did not understand the lesson completely, so she also could not correct her error perfectly, despite the clear clue from the teacher.

o. Elicitation - Self Repair

Based on the data, the elicitation - self repair sequence happened four times. Based on all four elicitation - self repair orders that happened in the class, all the learners were aware that they made an error and provided the correction, after the teacher's elicitation.

p. Elicitation - Peer Repair, Elicitation - Different Error

Based on the writer's data, these two oral CF and learners' uptake sequence happened in one conversation, with each of the sequence happened once. Previously the learner did not fully understand the teacher's first elicitation, leading into a different error. After that the teacher provided second elicitation to prompt the learner to correct the error, but instead of the learner who made the error, another learner corrected the error. From the writer's perspective, there was possibility that the first learner (who made the error) did not understand the question clearly. This could happen because she did not correct the error, but another learner corrected the error.

\section{q. Elicitation - Hesitation}

Based on the data, this oral CF and learner's uptake sequence only happened once. The learner hesitated to respond to the teacher's elicitation. Hesitation could happen because the learner did not know the correct answer. In the end, the teacher provided the correct answer completely, which was responded by repetition and then following by acknowledgement.

The writer had concluded from the findings about the teacher's oral CF and learners' uptake that happened in the class. Firstly, the writer found that the teacher used several types of oral CF proposed by Sheen and Ellis (2011) and didactic recasts was the mostly used type by the teacher, with total 15 out of 43 oral CF that occurred in the class. Secondly, the writer found out that following the teacher's oral CF, learners used several uptake types proposed by Panova and Lyster (2002), and repetition was the mostly used type by the learners, with total 12 out of 41 uptakes that occurred in the class. Lastly, the writer found out that mostly, learners gave response to teacher's oral CF (41 out of 43), although there were 2 oral CF which did not result in uptake. Didactic recasts - repetition was also found to be the mostly occurring sequence in the class. The teacher may prefer to give the correction directly to the learners, so that they can just repeat the correct answer given.

It can be interpreted that oral CF and learners' uptake were indeed helpful for learners in improving their second language skills. Learners mostly gave their uptake to teacher's oral CF and the teacher mostly made sure that uptake from learners happened. Those uptakes elicited from teacher's oral CF indicated that the learners acquired something for their language learning. However, there were some situations when the oral CF did not result in uptake. There may be several reasons of why uptake did not happen. Firstly, the learner took too much time to respond, and the teacher wanted to continue the lesson. Secondly, the teacher may assume that the learner 
had supposedly already known the correct answer through prior explanation. There was situation too when the uptake did not successfully repair the problem, but the teacher still continued the lesson. This could happen because the teacher did not want to take a longer time focusing on the particular problem, so the teacher continued the lesson. From those situations, it can also be interpreted that learners' uptake did not necessarily happen because of some classroom circumstances, which was considered as inevitable situation because the teacher also needed to focus on other things in order that the class could run smoothly.

\section{CONCLUSION}

In conclusion, teacher's oral CF could result in learners' uptake, which indicates that learners acquired something from the lesson. The oral CF that the teacher gave could make the learners aware of their errors and improve their second language skills. However, learners' uptake may not necessarily happen because of some circumstances. Learners' overlong correction and the awareness of the correction through prior explanation could be the reasons of none uptake given by the learners. Those reasons could be considered as inevitable situations as the teacher also had to think about the class continuation.

\section{REFERENCES}

Elliott, J. (2005). Using narrative in social research: Qualitative and quantitative approaches. London, UK: Sage Publications, Ltd.

Ellis, R. (2009). Corrective feedback and teacher development. L2 Journal, 1, 3-18

Dörnyei, Z. (2007). Research methods in applied linguistics: Quantitative, qualitative, and mixed methodologies. Oxford: Oxford University Press.

Lewis, G. 2007. Teenagers. Oxford: OUP

Littlewood, W. (1984). Foreign and second language learning: language acquisition research and its implications for the classroom. New York: Cambridge University Press.

Lyster, R., and Ranta, L. (1997). Corrective feedback and learner uptake: Negotiation of form in communicative classrooms. Studies in Second Language Acquisition, 19(1), 37-61.

Lyster, R., Saito, K., and Sato, M. (2013). Oral corrective feedback in second language classrooms. Language Teaching, 46(1), 1-40. doi:10.1017/S0261444812000365.

Méndez, E. H., Arguelles, L. G., \& Castro, A. B. J. (2011). Oral corrective feedback: Some ways to go about it. Memorias del VI Foro de Estudios en Lenguas Internacional (FEL 2010), 254-270. Retrieved from http://fel.uqroo.mx/adminfile/files/memorias/hernandez_mendez_edith_et_al.pdf.

Panova, I. and Lyster, R. (2002). Patterns of corrective feedback and uptake in an adult esl classroom. TESOL Quarterly, Vol. 36, No. 4 (Winter, 2002), pp. 573-595

Sheen, Y and Ellis, R. (2011). Corrective feedback in language teaching. Handbook of Research in Second Language Teaching and Learning. 2. 593-610.

Walsh, S. (2011). Exploring classroom discourse: Language in action. New York: Routledge. 